\title{
Research
}

Sadia Ahmed, Anne Heaven, Rebecca Lawton, Gregg Rawlings, Claire Sloan and Andrew Clegg

\section{Behaviour change techniques in personalised care planning for older people:}

\author{
a systematic review
}

\begin{abstract}
\section{Background}

Personalised care planning (PCP) interventions have the potential to provide better outcomes for older people and are a key focus in primary care practice. Behaviour change techniques (BCTs) can maximise effectiveness of such interventions, but it is uncertain which $\mathrm{BCTs}$ are most appropriate in PCP for older adults.
\end{abstract}

Aim

To identify BCTs used in successful PCP interventions for older people aged $\geq 65$ years.

\section{Design and setting}

Systematic review.

\section{Method}

The authors searched 12 databases from date of inception to 30 September 2017. They identified randomised controlled trials (RCTs) of interventions involving participants aged 265 years, and contextually related to PCP. Five areas of risk of bias were assessed. The Michie et al, BCT taxonomy was used for coding.

\section{Results}

Twenty-three RCTs involving 6489 participants (average age 74 years) described PCP interventions targeting the general older adult population and older people with specific longterm conditions lfor example, heart disease, diabetes, stroke). Just over half of the studies were deemed to be at a low risk of bias. Eleven 'promising' BCTs were identified in five trials reporting significant improvements in quality of life (QoL). Six BCTs were reported in all five of these trials: 'goal setting', 'action planning', 'problem solving', 'social support', 'instructions on how to perform a behaviour', and

'information on health consequences'. Modes of delivery varied.

\section{Conclusion}

Future PCP interventions to improve QoL for people aged $\geq 65$ years may benefit from focusing on six specific BCTs. Better reporting of BCTs would enhance future design and implementation of such interventions.

\section{Keywords}

behaviour change techniques; older people personalised care planning; quality of life randomised controlled trial; systematic review.

\section{INTRODUCTION}

Personalised care planning (PCP), defined as 'Explicitly engaging patients in a shared decision-making process involving both goal setting and action planning,", embodies core principles of 'person centredness' and 'shared decision making' embedded in the NHS for the past 20 years. ${ }^{2-6}$ The aim of PCP is to support individuals to self-manage their own health and wellbeing, typically using behaviour change techniques (BCTs) to help achieve collaborative outcomes. The PCP process enables linkage to additional mechanisms for improving outcomes, including improved care coordination and better access to community resources."? Recognised key outcomes of PCP are improved physical and mental health, selfmanagement capabilities, health-related behaviours, and changes in health service use. ${ }^{1,}$

In the UK, the publication in 2018 of the Comprehensive Model of Personalised Care consolidated evidence demonstrating PCP as a promising approach to achieve change (Figure 1). ${ }^{7}$ This informed the 2019 NHS Long Term Plan, and the linked work programme to implement personalised

S Ahmed, MSc, postgraduate researcher Leeds Institute of Clinical Trials Research, Clinical Trials Research Unit, University of Leeds, Leeds. A Heaven, BA, MPhil, PROSPER Research programme manager, Academic Unit for Ageing and Stroke Research, University of Leeds, Bradford Institute for Health Research, Bradford Royal Infirmary, Bradford. R Lawton, BA, PhD, PGDip AppPsych, professor, Psychology of Healthcare, School of Psychology, University of Leeds, Leeds; director, NIHR Yorkshire and Humber Patient Safety Translational Research Centre, Bradford. G Rawlings, MSc, PhD, trainee clinical psychologist, School of Clinical Psychology, University of Sheffield, Sheffield. C Sloan, MSc, $\mathrm{PhD}$, research fellow, MODS/BASIL Programme Mental Health and Addiction Research Group, Department of Health Sciences, Faculty of Sciences, University of York, York. A Clegg. BSc MD, MRCP, professor of geriatric medicine, care nationally. ${ }^{8}$ As part of the NHS Long Term Plan, the NHS England Ageing Well programme specifies a multidisciplinary team approach to care for older people (generally defined as $\geq 65$ years) defined as anticipatory care. Both personalised and anticipatory care were included in the draft 2020 primary care network direct enhanced service (PCN DES) specifications, but implementation was paused after the initial consultation period.? Personalised care plans for people eligible for anticipatory care - for example, those with frailty establish linkage across the individual specifications that are expected to form part of future GP contract negotiations.

The pause in implementation of the anticipatory and personalised care elements of the PCN DES allows reflection on how PCP services could be optimally designed for older people. Use of BCTs to help support development of selfmanagement capabilities is recognised as central to successful PCP. BCTs can maximise intervention effectiveness by helping individuals achieve and sustain behaviour change, ${ }^{10}$ but the effectiveness of particular BCTs may vary across the life course, and it is currently unclear which
University of Leeds, Leeds; honorary consultant geriatrician, Bradford Royal Infirmary, Bradford theme lead, NIHR ARC Yorkshire \& Humber Improving Care for Older People with Frailty theme, Bradford.

\section{Address for correspondence}

Anne Heaven, Academic Unit for Ageing and Stroke Research, University of Leeds, Bradford Institute for Health Research, Bradford Royal Infirmary, Duckworth Lane, Bradford BD9 6RJ, UK.

Email: anne.heavenabthft.nhs.uk

Submitted: 23 March 2020; Editor's response: 18 May 2020; final acceptance: 6 August 2020. CThe Authors

This is the full-length article (published online 26 Jan 2021) of an abridged version published in print. Cite this version as: Br J Gen Pract 2021; DOI: https://doi.org/10.3399/bjgp20X714017 


\section{How this fits in}

Wider implementation of personalised care planning (PCP) is included in national policy in the linked NHS England Personalised Care and Ageing Well programmes, and is expected to be included in the 2021-2022 GP contract negotiations. Behaviour change techniques (BCTs) are central to implementation of PCP, but are contextual, and not all BCTs are appropriate for use with older people laged $\geq 65$ years). Building on the current policy and operational focus on implementation of PCP for older people in primary care, this review supports the targeted intervention component of the comprehensive personalised care model by identifying six specific BCTs that have been successfully used in interventions to improve quality of life for older people.

BCTs are most relevant and effective in PCP for older people.

The Michie et al BCT taxonomy ${ }^{11}$ identifies 93 BCTs, enabling accurate identification and replication of intervention components and classification, and extraction of BCTs for the purpose of systematic reviews. ${ }^{12}$ The taxonomy has been used to identify the BCTs most prevalent and effective for various population groups and behaviours, and can help to develop interventions with a particular set of theoretical determinants underpinning behaviour. ${ }^{13}$ BCTs, used alone or in combination, map onto nine intervention functions (IFs) acting as broader mechanisms
Figure 1. Behaviour change techniques (BCT) within the Comprehensive Personalised Care model. LTCs = long-term conditions. for change. Identifying IFs alongside $\mathrm{BCT}$ s indicates which behavioural change mechanisms might work best. Healthcare and allied professionals are increasingly trained in and use BCTs and IFs to inform practice and interactions with clients. ${ }^{13}$

The aim of this review was to identify relevant BCTs for use with older people to inform the development of the Personalised Care Planning for Older People with Frailty (PROSPER) intervention as part of a National Institute for Health Research Programme Grant for Applied Research (NIHR PGfAR). ${ }^{14}$

The objectives were to:

- systematically identify and describe randomised controlled trials (RCTs) evaluating PCP in older people (with or without frailty), examining health, behaviour, and quality of life (QoL) outcomes;

- identify behaviour change elements in these studies, exploring the potential effectiveness of BCTs in improving QoL outcomes for older people in the context of PCP.

\section{METHOD}

\section{Search strategy}

This review followed PRISMA guidelines. ${ }^{15}$ A systematic search was implemented in MEDLINE, PsycINFO, EMBASE, CINAHL, AMED, PubMed, Scopus, Applied Social Science Index, British Nursing Index, Health Technology Assessment, Cochrane Central Register of Controlled Trials, and the Cochrane Database of Systematic Reviews. Databases were searched from date of inception to 30 September 2017. Search terms were developed in collaboration with an information specialist.

\section{Eligibility criteria}

This review focused on randomised controlled trials (RCTs) and cluster RCTs of interventions contextually related to PCP, that is, including 'goal setting' and 'action planning.' Interventions had to:

- focus on one-to-one PCP lnot group education);

- incorporate active involvement of the patients in a collaborative or shared decision-making process;

- include collaborative goal setting and action planning;

- include patient-based outcomes, for example, QoL and self-efficacy;

- encourage patients to set their own goals or priorities, and offer choices; and 


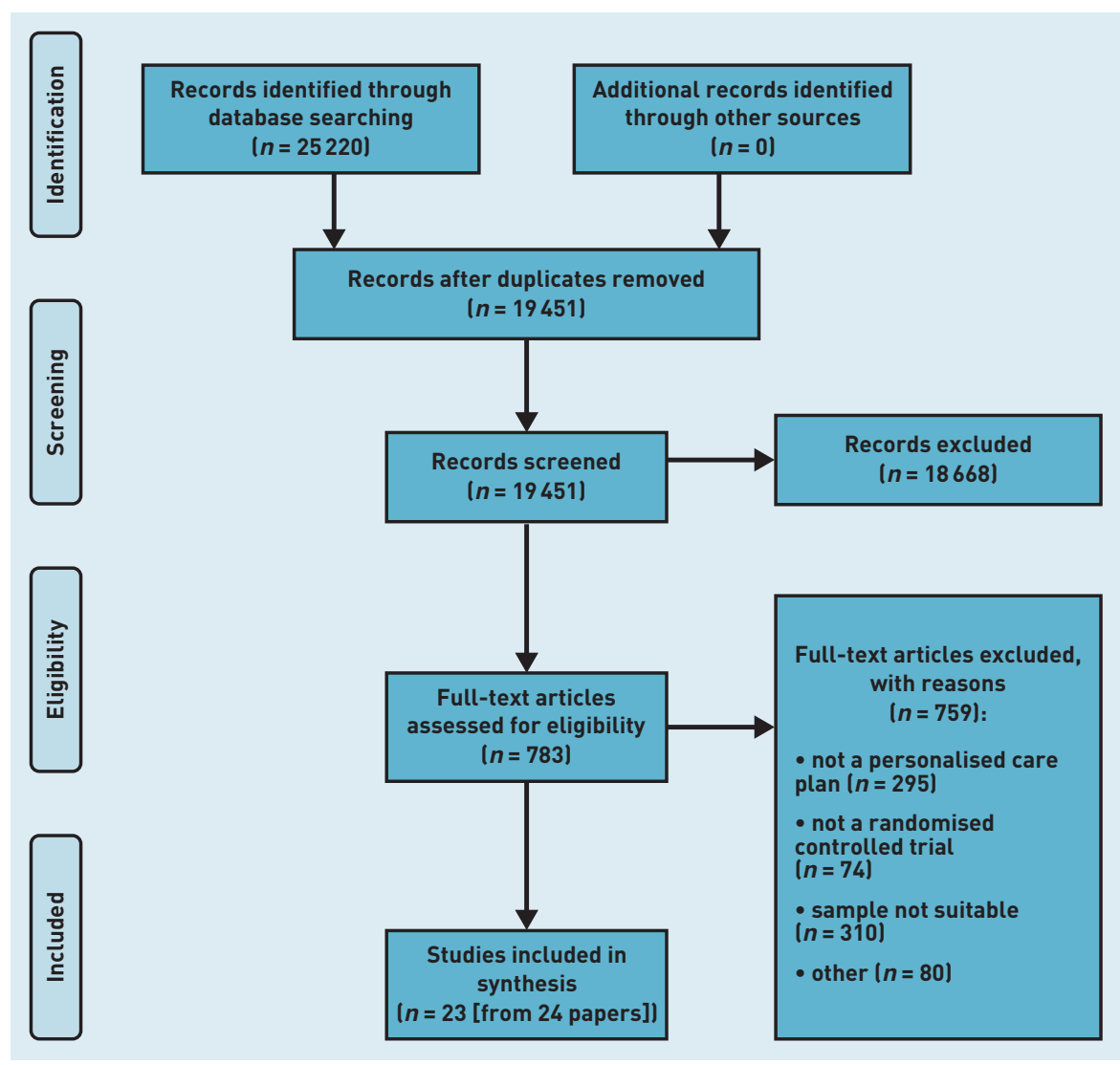

Figure 2. PRISMA flow diagram.
- actively involve patients in planning treatment or care.

Studies had to include participants aged $\geq 65$ years, or $\geq 50$ years if the sample mean age was $\geq 65$ years. Settings could include care homes, the community, and inpatient units.

\section{Screening}

All reviewers screened the first 40 titles and abstracts from retrieved articles to ensure consistency in applying inclusion and exclusion criteria. The remainder of the articles were divided equally between the four reviewers. Following this, full texts of potentially eligible relevant articles were obtained. Full texts were divided equally between five reviewers, then screened, and reasons for exclusion recorded. Papers initially selected for inclusion were screened again and consensus was reached for the final list.

\section{Data extraction}

Four reviewers extracted data, and 10\% of the extractions were double-checked by another member of the team. Three reviewers with BCT taxonomy coding training ${ }^{12}$ independently coded all BCTs explicitly reported in both intervention and control conditions. It was important to note if specific/different BCTs were being used in the controls or as part of usual care as they may also affect outcomes. Table 1 shows the frequency of 'promising BCTs' in both intervention and control arms.

Coding was reviewed by the whole team, and disparities resolved by consensus. Two reviewers replicated the process to code IFs. In an attempt to capture all relevant BCTs, the authors coded those that were definitely $(++)$ and probably $(+)$ present. $^{2}$ They used BCT domain headings as codes when there was a lack of information to specify a technique. One of the authors who is a behaviour change expert provided advice and input on coding

Using the Brown et al approach, ${ }^{16}$ the authors defined a BCT as 'promising' based on frequency (included in $\geq 25 \%$ interventions) and being present in at least two effective interventions, that is, those that reported statistically significant differences $(P<0.05)$ at the latest available follow-up.

\section{Risk of bias assessment}

Each reviewer assessed five areas of risk of bias using the Cochrane Collaboration Tool. ${ }^{17}$ Each entry was rated as low, high, or unclear risk, with $10 \%$ of assessments double-checked by a second reviewer and disagreements resolved by consensus. This assessment was not used to exclude studies or weight the findings, but to highlight where systematic error may have occurred.

\section{Data analysis}

Findings were summarised using a narrative approach.

\section{RESULTS}

\section{Literature search}

The search identified 19451 unique articles. Following title/abstract screening, 783 fulltext articles were assessed for eligibility, of which 759 were excluded. Twenty-three interventions reported in 24 articles met the criteria for inclusion (Figure 2).

\section{Study characteristics}

There were 6489 participants (mean age 74 years) across 23 studies. Eleven of the 23 studies were conducted in the US and Canada, ${ }^{18-28}$ eight in Asia, ${ }^{29-36}$ two in Europe, ${ }^{37,38}$ and two in the UK. ${ }^{39,40}$ Most participants were female. Eleven of the studies focused on general older adult populations, six on participants with heart disease or angina, $29,30,36,38-40$ two on those with diabetes, ${ }^{23,31}$ two on stroke survivors, ${ }^{21,37}$ and two on nursing home residents. ${ }^{34,35}$ 


\section{Table 1. Promising behaviour change techniques}

\begin{tabular}{|c|c|c|c|}
\hline Behaviour change technique & Example & Interventions, $n$ & Controls, $m^{2}$ \\
\hline Action planning & $\begin{array}{l}\text { Agreeing to eat three light meals a day, with at least one hot meal. } \\
\text { Action planning needs to include thought about when, where, and } \\
\text { how the behaviour will take place }\end{array}$ & 23 & 0 \\
\hline Goal setting (outcome) & $\begin{array}{l}\text { Goals generally need to be specific, measurable, achievable, relevant, } \\
\text { and time bound (SMART), and the result of shared decisions. For } \\
\text { example, getting to the shops and home without assistance }\end{array}$ & 21 & 0 \\
\hline Social support (unspecified) & Getting a 'blue badge' to allow the person to go to the shops alone & 21 & 2 \\
\hline Problem solving & $\begin{array}{l}\text { Working to identify the barriers preventing individuals from engaging in } \\
\text { behaviours and identifying 'enablers'. For example, not being able to } \\
\text { get to a social group because of lack of transport; problem solving should } \\
\text { address how they might access the group }\end{array}$ & 19 & 0 \\
\hline Information on health consequences & $\begin{array}{l}\text { General education: information about the benefits of drinking enough } \\
\text { water (hydration), or the negative effects of consumption of sugary foods } \\
\text { if they have diabetes }\end{array}$ & 19 & 6 \\
\hline Pharmacological support & $\begin{array}{l}\text { Using pharmacological support, including appetite stimulation, to } \\
\text { improve the appetite in patients with weight loss }\end{array}$ & 14 & 4 \\
\hline $\begin{array}{l}\text { Instructions on how to perform a } \\
\text { behaviour }\end{array}$ & Advising how to use online services from the local council & 13 & 1 \\
\hline Verbal persuasion about capability & $\begin{array}{l}\text { Focusing on an individual's abilities and assets, and providing verbal } \\
\text { encouragement }\end{array}$ & 12 & 0 \\
\hline Review outcome goals & $\begin{array}{l}\text { Checking if goals have been achieved, and exploring barriers to } \\
\text { achievement }\end{array}$ & 9 & 0 \\
\hline Biofeedback & Breathing exercises and monitoring with spirometer & 4 & 0 \\
\hline
\end{tabular}

Five studies focused specifically on older people with Medicare insurance. $22,24,25,27,28$ Two studies focused specifically on older people with frailty, although frailty was not defined. 18,20 Although more than half the trials explicitly mentioned behaviour change theory, details varied widely.

Delivery settings included participants homes $(n=9), 18-24,27,28 \quad$ hospitals $(n=5), 26,29,30,33,38$ primary care practices $(n=4)^{24,25,32,39}$ and a nursing home $(n=1) .{ }^{34}$ Modes of intervention delivery included online, via telephone, and face-to-face. Eleven interventions ${ }^{18-20,24,25,27-30,36,38}$ used both face-to-face and telephone delivery. Almost half of the interventions (10/23) were delivered by nurses. 18,24,25,28-30,32,38-40 Other delivery agents were $\mathrm{GPs}^{39}$ occupational therapists, ${ }^{37}$ volunteers, ${ }^{20}$ and researchers. ${ }^{36}$

The majority of interventions aimed to improve self-care or self-management of a disease. Others aimed to improve participants independence in their homes; ${ }^{21,37}$ ability to carry out activities of daily living, ${ }^{37}$ or engagement in therapy. ${ }^{26}$ Some also aimed to reduce use of health services. ${ }^{24}$ Supplementary Table S1 contains detailed information on study characteristics.

\section{Risk of bias assessment}

Eleven of 23 studies scored low on the majority of the criteria for risk of bias. ${ }^{18,20,23,26,27,29-31,33-37}$ Generally, there was insufficient information on method of randomisation, allocation concealment, and blinding, but a high risk of bias was observed on "blinding of participants and personnel'..$^{17}$ Only one study ${ }^{18}$ had a green risk assessment in this area. All other studies were either amber or red. The red, amber, and green assessment of risk for each of the criterion is shown in Supplementary Table S2.

\section{Findings}

Seventeen of the 23 studies reported statistically significant findings on one or more outcome measure between groups $23,30,33,35$ or a within-group difference over time. ${ }^{31}$ There were significant findings relating to mortality and diseasespecific outcomes in five studies. ${ }^{2,27,30,31,36}$ Five studies demonstrated significant 
improvements in mental health outcomes. ${ }^{23,32,34,35,40}$ Five also showed significant improvements in behavioural outcomes such as physical activity or attendance at fitness classes, ${ }^{25,26,28,29,33}$ and five for QoL outcomes. ${ }^{23,30,31,33,35}$

\section{Behaviour change techniques}

Intervention groups. Forty-seven of the 93 BCTs in the taxonomy were reported in the intervention groups. Supplementary Table S3 summarises the BCTs used in intervention and control groups.

Control groups. Twelve BCTs were identified in the control groups, with the most common ones being 'social support' (practical), "information about health consequences', 'credible source', and 'pharmacological support'.

Intervention functions. Six of the nine IFs were coded. Table 2 shows persuasion coded for all interventions. 'Enablement' and 'education' were also prevalent. Most studies satisfied more than one IF. The mean number of IFs per study was three. 'Incentivisation', 'coercion', and 'restriction' were not coded. Many interventions provided some form of lifestyle information or education. For more detailed intervention descriptions, including significance, see Supplementary Table S4.

Promising behaviour change techniques in trials reporting quality of life outcomes. There were 11 trials that included QoL as an outcome. Of these, five trials reported significant improvements for QoL, either between groups, 23,30,31,33,35 or within groups over time.31 One of the significant QoL interventions was web based. ${ }^{23}$ From these five trials, the authors identified 11 'promising' BCTs. Of the 11 promising BCTs, six were present in all five of the trials. These were: 'goal setting', 'action planning', 'problem solving', 'social support', "instructions on how to perform a behaviour", and 'information on health consequences'. 'Goal setting', divided into 'goal setting (behaviour)' and 'goal setting (outcome)', aligned with the BCT taxonomy. 'Unspecified social support', usually including advice, encouragement, or coaching, was also a promising BCT; emotional social support was rarely identified. Examples of all 11 BCTs are shown in Table 2

\section{DISCUSSION}

\section{Summary}

The authors identified 23 trials involving 6489 participants that used BCTs in the context of PCP interventions with older people. Interventions differed in terms of setting, mode of delivery, intervention provider, and reported outcomes.

Six of eleven promising BCTs were identified in five studies that showed improvements in QoL. Goal setting (behaviour) and goal setting (outcome) featured along with action planning, problem solving, social support, instructions on how to perform a behaviour, and information on health consequences. 'Emotional' social support was rarely mentioned, but 'unspecified' social support, including advice, encouragement, or coaching, was also noted as a promising BCT. This could be a function of interventions being delivered by healthcare professionals (HCPs) who have additional responsibilities and thus less available time to implement the emotional social support BCT. Alternatively, emotional social support may not have been explicitly mentioned where it is perceived as a naturalised component of an HCP's role. ${ }^{41}$ Many interventions provided some form of lifestyle information or education. The authors assumed that education provision would involve at least two BCTs - 'information on health consequences' and instructions on how to perform a behaviour."

BCTs were also coded in the control groups, which mostly comprised usual care. There was some overlap between the BCTs in usual care and intervention arms, with some BCTs - for example, 'pharmacological support' or 'credible source' - considered part of usual care.

The majority of interventions were delivered face-to-face, or via telephone and face-to-face. Face-to-face delivery seemed the most acceptable mode of delivery for an older population. However, one of the significant QoL interventions was web based. Others had elements of telephone follow-up. Flexibility in delivery mode may be useful in the context of COVID-19 and emerging new ways of working.

\section{Strengths and limitations}

This review focuses on BCTs within PCP interventions specifically for older adults laged $\geq 65$ years). The findings add value to the self-management approach outlined in the comprehensive personalised care model as they pertain to the specific needs of older adults who fall within the 30\% of the population with long-term physical or mental health conditions (including frailty) who need targeted interventions. They can easily be adopted by health and social care professionals working with this population 


\section{Funding}

This review was funded by the National Institute for Health Research (NIHR) Programme Grant for Applied Research (RP-PG-0216-20003). The views expressed are those of the authors and not necessarily those of the NIHR or the Department of Health and Social Care.

\section{Ethical approval}

This study was approved by Bradford Leeds Research Ethics Committee 18 Oct 2018 (18/YH/0294).

\section{Provenance}

Freely submitted; externally peer reviewed.

\section{Competing interests}

The authors have declared no competing interests.

\section{Acknowledgements}

The authors would like to thank members of the PROSPER programme management group for their review of this manuscript before submission, in particular their GP colleagues Louise Robinson, Sara Humphrey, and Robbie Foy, and lay member Marilyn Foster.

\section{Open access}

This article is Open Access: CC BY 4.0 licence (http://creativecommons.org/ licences/by/4.0/).

\section{Discuss this article}

Contribute and read comments about this article: bjgp.org/letters to enhance existing health coaching skills. The authors anticipate that review findings will be especially useful in any future implementation of personalised and anticipatory care. The focus on BCTs that improve quality of life in older age is aligned with the growing recognition that this is an important outcome for older people.

The review has limitations. All interventions used multiple BCTs, but it was not possible to assess the impact of individual BCTs on outcomes. The authors attempted to mitigate this by focusing on BCTs that occurred in all five studies with significant improvements in QoL.

The heterogeneity of interventions precluded meta-analysis, and lack of follow-up data meant the authors were unable to assess long-term effectiveness. Assessing risk of bias was also problematic as unblinding of participants and delivery staff is almost inevitable in PCP.

The authors only included randomised controlled trials in this review as they wanted to examine BCTs that had been utilised and tested for effectiveness and acceptability using the same design as their own intervention evaluation. Although this potentially missed studies, including alternative BCTs, the robust evaluation design increases confidence in review findings.

\section{Comparison with existing literature}

The authors used the pragmatic assumptions of Brown et al ${ }^{16}$ to define promising $\mathrm{BCT}$, enabling them to focus the BCT taxonomy ${ }^{11}$ and identify BCTs that are most useful in PCP for older people. This is particularly important as techniques appropriate for younger adults may not be effective for older adults. ${ }^{42}$

\section{Implications for research and practice}

Consistent use of the BCT taxonomy when reporting interventions in research studies would enable researchers to identify specific BCTs for use with specific target populations. More widespread inclusion of mediation analysis in RCTs of PCP interventions in older age would help inform which individual BCTs are most effective.

The review findings are especially relevant for the current English primary care context, as they can be used to inform operational implementation of the proposed PCN DES personalised and anticipatory care service specifications. 


\section{REFERENCES}

1. Coulter A, Entwistle VA, Eccles A, et al. Personalised care planning for adults with chronic or long-term health conditions. Cochrane Database Syst Rev 2015; (3): CD010523. DOI: 10.1002/14651858.CD010523.pub2.

2. NHS England. Five year forward view. 2014. https://uww.england.nhs.uk/ wp-content/uploads/2014/10/5yfv-web.pdf laccessed 21 Dec 2020).

3. Diabetes UK, The Health Foundation, NHS National Diabetes Support Team. Year of Care Partnerships. Getting to grips with the year of care: a practical guide. 2008. https://wnw.yearofcare.co.uk/sites/default/files/images/Getting\%20to\%20 Grips\%20with\%20the\%20Year\%20of\%20Care\%20A\%20Practical\%20Guide.pdf (accessed 21 Dec 2020)

4. Department of Health and Social Care. The NHS constitution for England. Updated 14 October 2015. https://mww.gov.uk/government/publications/thenhs-constitution-for-england/the-nhs-constitution-for-england laccessed 21 Dec 2020).

5. Department of Health. National service framework for older people. 2001. https://assets.publishing.service.gov.uk/government/uploads/system/uploads/ attachment_data/file/198033/National_Service_Framework_for_Older_People.pdf (accessed 21 Dec 2020)

6. Department of Health. Equity and excellence: liberating the NHS. 2010. https:// assets.publishing.service.gov.uk/government/uploads/system/uploads/ attachment_data/file/213823/dh_117794.pdf (accessed 21 Dec 2020).

7. NHS England. Comprehensive model of personalised care. 2019. https://nww. england.nhs.uk/publication/comprehensive-model-of-personalised-care/ (accessed 21 Dec 2020).

8. NHS England. The NHS long term plan. 2019. https://umw.longtermplan.nhs.uk/ publication/nhs-long-term-plan/ (accessed 21 Dec 2020).

9. NHS England, NHS Improvement. Network contract direct enhanced service. Draft outline service specifications. 2019. https://wnw.engage.england.nhs.uk/ survey/primary-care-networks-service-specifications/supporting_documents/ Draft\%20PCN\%20Service\%20Specifications\%20December\%202019.pdf laccessed 21 Dec 2020).

10. Presseau J, Ivers NM, Newham JJ, et al. Using a behaviour change techniques taxonomy to identify active ingredients within trials of implementation interventions for diabetes care. Implementation Science 2015; 10(1): 55.

11. Michie S, van Stralen MM, West R. The behaviour change wheel: a new method for characterising and designing behaviour change interventions. Implementation Science $2011 ; \mathbf{6}(1): 42$.

12. Wood CE, Richardson M, Johnston M, et al. Applying the behaviour change technique (BCT) taxonomy v1: a study of coder training. Transl Behav Med 2015; 5(2): 134-148.

13. Heath G, Cooke R, Cameron E. A theory-based approach for developing interventions to change patient behaviours: a medication adherence example from paediatric secondary care. Healthcare 2015; 3(4): 1228-1242.

14. Heaven A, Bower P, Cundill B, et al. Study protocol for a cluster randomised controlled feasibility trial evaluating personalised care planning for older people with frailty: PROSPER V2 27/11/18. Pilot and Feasibility Studies 2020; 6(1): 56.

15. Moher D, Liberati A, Tetzlaff J, et al. Preferred reporting items for systematic reviews and meta-analyses: the PRISMA statement. PLoS Med 2009; 6(7): e1000097.

16. Brown TJ, Hardeman W, Bauld L, et al. A systematic review of behaviour change techniques within interventions to prevent return to smoking postpartum. Addict Behav 2019; 92: 236-243.

17. Higgins JPT, Altman DG, Gøtzsche PC, et al. The Cochrane Collaboration's tool for assessing risk of bias in randomised trials. BMJ 2011; 343: d5928.

18. Hall N, Beck P, Johnson D, et al. Randomized trial of a health promotion program for frail elders. Canadian J Aging/La Revue Canadienne du Vieillissement 1992; 11(1): 72-91.

19. Hogg W, Lemelin J, Dahrouge S, et al. Randomized controlled trial of anticipatory and preventive multidisciplinary team care: for complex patients in a communitybased primary care setting. Can Fam Physician 2009; 55(12): e76-e85.

20. Laforest S, Nour K, Gignac MA, et al. The role of social reinforcement in the maintenance of short-term effects after a self-management intervention for frail housebound seniors with arthritis. Can J Aging 2012; 31(2): 195-207.

21. Markle-Reid M, Orridge $C$, Weir R, et al. Interprofessional stroke rehabilitation for stroke survivors using home care. Can J Neurol Sci2011; 38(2): 317-334.
22. Alkema GE, Wilber KH, Shannon GR, Allen D. Reduced mortality: the unexpected impact of a telephone-based care management intervention for older adults in managed care. Health Serv Res 2007; 42(4): 1632-1650.

23. Bond GE, Burr RL, Wolf FM, Feldt K. The effects of a web-based intervention on psychosocial well-being among adults aged 60 and older with diabetes: a randomised trial. Diabetes Educ 2010; 36(3): 446-456.

24. Boult C, Leff B, Boyd CM, et al. A matched-pair cluster-randomized trial of guided care for high-risk older patients. J Gen Intern Med 2013; 28(5): 612-621.

25. Holland SK, Greenberg J, Tidwell L, et al. Community-based health coaching, exercise, and health service utilisation. J Aging Health 2005; 17(6): 697-716.

26. Lenze EJ, Host HH, Hildebrand MW, et al. Enhanced medical rehabilitation increases therapy intensity and engagement and improves functional outcomes in post-acute rehabilitation of older adults: a randomised controlled trial. J Am Med Dir Assoc 2012; 13(8): 708-712.

27. Mayer JA, Jermanovich A, Wright BL, et al. Changes in health behaviours of older adults: the San Diego Medicare Preventive Health Project. Prev Med 1994; 23(2): 127-133.

28. Meng H, Wamsley BR, Friedman B, et al. Impact of body mass index on the effectiveness of a disease management-health promotion intervention on disability status. Am J Health Promot 2010; 24(3): 214-222.

29. Zhao Y, Wong FKY. Effects of a post-discharge transitional care programme for patients with coronary heart disease in China: a randomised controlled trial. $J$ Clin Nurs 2009; 18(17): 2444-2455.

30. Yu DSF, Lee DTF, Stewart S, et al. Effect of nurse-implemented transitional care for Chinese individuals with chronic heart failure in Hong Kong: a randomised controlled trial. J Am Geriatr Soc 2015; 63(8): 1583-1593.

31. Moriyama M, Nakano $M$, Kuroe $Y$, et al. Efficacy of a self-management education programme for people with type 2 diabetes: results of a 12-month trial. Jpn J Nurs Sci2009; 6(1): 51-63.

32. Kwon SH. Wheel of wellness counseling in community dwelling Korean elders: a randomised, controlled trial. J Korean Acad Nurs 2015; 45(3): 459-468.

33. Song HY, Yong SJ, Hur HK. Effectiveness of a brief self-care support intervention for pulmonary rehabilitation among the elderly patients with chronic obstructive pulmonary disease in Korea. Rehabil Nurs 2014; 39(3): 147-156.

34. Park YH, Chang $\mathrm{H}$. Effect of a health coaching self-management programme for older adults with multimorbidity in nursing homes. Patient Prefer Adherence 2014; 8: 959-970.

35. Park YH, Moon SH, Ha JY, Lee MH. The long-term effects of the health coaching self-management programme for nursing-home residents. Clin Interv Aging 2017; 12: 1079-1088.

36. Zhao JH, Chang AM, Edwards $\mathrm{H}$, et al. A randomised controlled trial of selfmanagement programme improves health-related outcomes of older people with heart failure. J Adv Nurs 2013; 69(11): 2458-2469.

37. Bertilsson AS, Ranner M, von Koch L, et al. A client-centred ADL intervention: three-month follow-up of a randomized controlled trial. Scand J Occup Ther. 2014; 21(5): 377-391.

38. Leventhal ME, Denhaerynck K, Brunner-La Rocca HP, et al. Swiss Interdisciplinary Management Programme for Heart Failure (SWIM-HF): a randomised controlled trial study of an outpatient inter-professional management programme for heart failure patients in Switzerland. Swiss Med Wkly 2011; 141: w13171.

39. Murphy AW, Cupples ME, Smith SM, et al. Effect of tailored practice and patient care plans on secondary prevention of heart disease in general practice: cluster randomised controlled trial BMJ 2009; 339: b4220.

40. Lewin RJP, Furze G, Robinson J, et al. A randomised controlled trial of a selfmanagement plan for patients with newly diagnosed angina. Br J Gen Pract 2002; 52(476): 194-196, 199-201.

41. Neri L, Brancaccio D, Rocca Rey LA, et al. Social support from health care providers is associated with reduced illness intrusiveness in haemodialysis patients. Clin Nephrol 2011; 75(2): 125-134.

42. French DP, Olander EK, Chisholm A, McSharry J. Which behaviour change techniques are most effective at increasing older adults' self-efficacy and physical activity behaviour? A systematic review. Ann Behav Med 2014; 48(2): 225-234. 